\title{
Physico-Chemical Characterization of Agricultural Residues as Precursors for Activated Carbon Preparation

\author{
Short Title: Precursors for activated carbon preparation
}

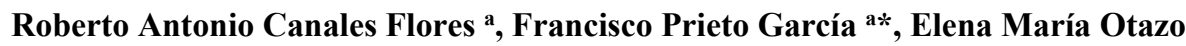 \\ Sánchez a , Ana María Bolarín Miró ${ }^{\mathrm{b}}$, Otilio Arturo Acevedo Sandoval a \\ ${ }^{a}$ Academic Area of Chemistry, bAcademic Area of Materials and Earth Sciences. \\ Autonomous University of Hidalgo State, Road Pachuca-Tulancingo km 4.5, C.P. 42186. \\ Pachuca, Hidalgo, Mexico. \\ * Corresponding author. E-mail address: prietog@uaeh.edu.mx (F. Prieto García)
}

\begin{abstract}
Biomass is a promising alternative and renewable energy source that can be transformed into other value-added products such as activated carbon. In this research, barley husk, corn cob and Agave salmiana leaves were characterized to determine their chemical composition and morphology to evaluate their potentiality as precursors of activated carbons. Based on the main composition results obtained, the biomass samples have suitable chemical and physical characteristics to be considered as good precursors of activated carbons, such as carbon contents greater than $40 \%$, ash content less than $10 \%$, moisture content less than $30 \%$, high volatile contents with values from 75 to $80 \%$ and a porous and fibrous morphology. The results indicate that the main compositions in the biomass were cellulose and lignin. The cellulose content was more than lignin (15-26\%) for the residues selected. Specifically, $\alpha$-cellulose contents with values from $52 \%$ to $79 \%$, $\beta$-cellulose contents of $13-44 \%, \gamma$-cellulose contents less than $11 \%$, and holocellulose contents of $82-83 \%$ were determined. The thermal decomposition for the biomass samples proceeded with five stages attributed to the evaporation of some volatile compounds $\left(70-150{ }^{\circ} \mathrm{C}\right)$, to the degradation of hemicellulose $\left(180-230{ }^{\circ} \mathrm{C}\right)$, to the cellulose volatilization $\left(250-350^{\circ} \mathrm{C}\right)$, to the lignin decomposition $\left(380-550^{\circ} \mathrm{C}\right)$, and to the degradation of complex polymers and inorganic salts, respectively. The stage corresponding to the cellulose decomposition showed rapid mass decreased in the three residues. This results show that the cellulose and lignin content is another important parameter to evaluate the pyrolysis characteristics of a good precursor of activated carbon.
\end{abstract}

Keywords: activated carbon; barley husk; corn cob; agave leaves; biomass; thermogravimetry

\section{Introduction}

Biomass is a complex biological organic or non-organic solid product derived from living or living organism and available naturally. Lignocellulosic biomass is considered a promising alternative and renewable energy source that can be transformed by pyrolysis process into other value-added products such as activated carbon and bio-oil (Stefanidis et al. 2014). Currently, agricultural and forest residues have found use as raw material for other applications (Ioannidou and Zabaniotou 2007). According to Stefanidis et al. (2014), large amounts 
of lignocellulosic waste are produced each year causing environmental problems. For this reason, one of the ways currently available to reduce the amount of waste generated by agro-industry is the recovery following the principles of green chemistry, which promotes the use of renewable raw materials from agricultural products to obtain new products with added value. Thus, a viable and environmentally responsible option is the transformation of agricultural residues into activated carbon to be applied and evaluated in various environmental pollution problems, preventing them from becoming soil and groundwater contaminants due to their inadequate final disposal (Canales-Flores and Prieto-García 2016).

Significant researches have been devoted to the production of activated carbons from agricultural residues because of availability and low cost (Ioannidou and Zabaniotou 2007). Wood, corn straw, olive stones, bagasse, sugar cane bagasse, almond shells, corn stover, apricot stones, nut shells, corn cob, rice husk and rice straw are some examples of biomass used for obtaining activated carbons (Ioannidou and Zabaniotou 2007). Other studies have shown that the microporous structure and chemical surface of activated carbon as well as high carbon content make it useful for several industrial applications. Thus, in agriculture industry it is used to upgrade the soil quality, in purification industry it is used to remove heavy metals, and in textile industry it is used to dye removal (Ioannidou and Zabaniotou 2007).

According to Ioannidou and Zabaniotou (2007) production of activated carbons from the biomass does not only depend upon the process employed to produce but it is also a function of the process parameters involved in the production also. In recent years, several researchers have focused on the obtaining of carbonaceous materials from lignocelullosic biomass. They have shown that the production and properties of activated carbon depends upon several factors like biomass properties (type of biomass, moisture content, particle size and chemical composition), reaction conditions and other factors.

Regarding biomass properties, lignocellulosic biomass is composed mainly of three basic structural components: cellulose, hemicellulose and lignin (Khezami et al. 2005; Stefanidis et al. 2014). Cellulose is the main component, is a linear polysaccharide constituted by long chains of glucose residues. Its composition is C: 44.4\%, O: 49.4\% and H: 6.2\% in weight (Khezami et al. 2005). Hemicelluloses are relatively low-molecular weight non-cellulosic polysaccharides. Its elemental composition is about the same as that of cellulose. Lignin is a three-dimensional polymer made of phenylpropane units. Its composition is $\mathrm{C}: 62 \%, \mathrm{O}: 32 \%$ and $\mathrm{H}: 6 \%$ in weight, which differs from that of cellulose (Khezami et al. 2005). In addition to these components, lignocellulosic biomass also contains a small amount of inorganic material (ash) and extractives (Stefanidis et al. 2014). The content of cellulose, hemicellulose and lignin in biomass varies depending on the biomass type (Stefanidis et al. 2014).

Several literatures are available discussing the effect of biomass constituents on the activated carbon production. In this study, physical and chemical characterization of barley husk, corn cobs and agave leaves was discussed to evaluate its potential as precursors of activated carbons. 


\section{Materials and methods}

\section{Preparation of the precursors materials}

In this research, barley husk, corn cobs and Agave salmiana leaves were the lignocellulosic residues analyzed. These precursors were obtained from Almoloya and Apan in the State of Hidalgo, Mexico.

The raw materials were washed five times with distilled water, titrated in a food processor, dried at $105^{\circ} \mathrm{C}$ for $72 \mathrm{~h}$ in an oven, ground in a knife mill to obtain 0.3-1.0 mm particle size and finally sieved through 18 and 45 mesh sieves.

The proximate analysis was carried out according to the method described in ASTM Standard D3172 (1997), total sugars and fat according to the TAPPI T204 (1997), Klason lignin according to the TAPPI T222 (1998), holocellulose according to the method described by Wise et al. (1946), and $\alpha$-, $\beta$ - and $\gamma$ cellulose according to the TAPPI T203 (1999).

\section{Characterization of the precursors materials}

The raw materials were characterized by elemental analyses to know the content of $\mathrm{C}, \mathrm{H}$ and $\mathrm{N}$, laser diffraction particle size to analyze particle sizes distribution, thermogravimetry to study the transformations occurring in the precursor during carbonization, Fourier Transform infrared spectrophotometry to obtain information on the presence of functional groups, and scanning electron microscopy to observe the surface morphology of the precursors.

\section{Particle size}

Particle sizes distribution of the precursors materials was determined with a Beckman Coulter laser diffraction particle size analyzer model LS13-320.

\section{Elemental analyses}

Elemental analyses of C, $\mathrm{H}$ and $\mathrm{N}$ of dried samples were performed using a Perkin Elmer analyzer model 2400 PECHN-SO using acetanilide as the reference. The oxygen content was obtained indirectly by difference.

\section{Thermogravimetric analysis (TGA)}

The thermal behavior of the lignocellulosic precursors was performed with a Mettler-Toledo analyzer model TGA/SDTGA-851, under a nitrogen atmosphere, with a heat ramp of $10^{\circ} \mathrm{C} \min ^{-1}$ up to $600{ }^{\circ} \mathrm{C}$.

\section{Fourier Transform infrared spectrophotometry (FTIR)}

Spectra were recorded in a Perkin Elmer Spectrum one spectrometer. The samples were mixed with KBr powder and the mixture was pressed into pellet. The spectra were recorded in the region of 4000 to $370 \mathrm{~cm}^{-1}$, resolution 
of $4 \mathrm{~cm}^{-1}$ and 10 scans.

\section{Scanning electron microscopy (SEM)}

The surface morphology of the precursors materials was observed by means of SEM using a JEOL scanning electron microscope model JSM 6300 operated at $10 \mathrm{kV}$. For observation, particles of the precursors were dispersed onto carbon tape and coated with gold.

\section{Results and Discussion}

Results of physic-chemical characterization of the three residue materials are presented in Table 1. As shown, the moisture content of these residues was the same, around 7\%. Regarding this biomass constituent, Tripathi et al. (2016) mention that low moisture is advisable for the activated carbon production because it not only reduces the heat energy but it also lowers the time required for the process. Specifically, lignocellulosic precursors with more than $30 \%$ of moisture is not suitable for the pyrolysis since the greater amount of energy supplied to the biomass would be used in moisture removal present in it and rest would be used to increase its temperature. Added to this, they indicate that large amount of moisture (more than $40 \%$ ) reduces the heating rate resulting in more time in achieving the process temperature. In this sense, Demirbas (2004) and Xiong et al. (2013) observed that increase in moisture content in pyrolysis of wood and sewage sludge, respectively, decreases the yield of biochar. Thus, the moisture content of the three precursors of this study is suitable for the activated carbon production.

In contrast to the above mentioned, the literature indicates that the ash content is another important parameter in the activated carbon production since defines the quality of precursor in the combustion determining the content incombustible matter (Nieto-Delgado et al. 2011). Therefore, a low ash content is desired because it could negatively affect the yields to partially eliminate the formation of char (Pereira et al. 2014). In this research, the ash contents of precursors are less than $10 \%$ and are acceptable for the activated carbons production which is in accordance with the result obtained by other studies as shown in Table 1.

Regarding the content of volatile matter, the literature mentions that this parameter is responsible for the pores in the structures of carbonaceous materials as precursors after being subjected to elevated temperatures the volatile material contained in it is released resulting in the formation of porous structures (Canales-Flores and Prieto-García 2016). In this study, high volatile contents were found with values from $75 \%$ to $80 \%$. These values are very suitable for the subsequent pyrolysis since the gradual and controlled release of volatile matter result in the enrichment of carbon in the precursor and further more are within the range reported for other similar precursors used in the preparation of activated carbons: 69-84\% (Canales-Flores and Prieto-García 2016). Therefore, the volatile matter content is another important parameter because it provides an indication of the reactivity and ease of ignition of an organic material. In the same way, fixed carbon, sugars and fat contents are similar to those reported in other studies.

Other criterion for the selection of the biomass, for the activated carbon production, is the lignin and cellulose 
content present in the raw material. Table 1 shows the contents of lignocellulosic compounds. $\alpha$-cellulose contents from $52 \%$ to $79 \%$ were observed being agave leaves and barley husk which had the highest values. These results were superior to those reported in other studies as shown in Table 1. Such differences can be attributed to the extraction method used in this research, which is consistent with that reported by Espino et al. (2014) who conducted studies of chemical characterization of lignocellulosic materials as part of their investigation. On the other hand, $\beta$-cellulose contents of $44 \%$ were obtained for corn cob while agave leaves and barley husk showed lower content, ranging 13-22\%. Meanwhile, $\gamma$-cellulose contents less than $11 \%$ were determined. In contrast, high percentages of holocellulose of $82-83 \%$ were found (the term holocellulose represents the total cellulose, which is composed of cellulose and hemicelluloses).

Another structural material is lignin whose content for barley husk was $26 \%$ while agave leaves and corn cob had 15\%. The results obtained were consistent with those reported by (Kohli et al. 2013; Espino et al. 2014). From these results, it is shown that all of the biomass samples contain more cellulose than lignin. In this regard, Savova et al. (2001) observed that the porosity of the produced biochar varies with the composition of cellulose and lignin, and established that biomass with high lignin content produce biochar with macroporous structure while the plant biomass with high cellulose content produce biochar with microstructure. Therefore, knowledge of the values of lignocellulosic compounds is very important because the chemical composition of precursor has a direct influence on the properties of activated carbons, which is consistent with the findings of Pereira et al. (2014).

Table 1 Precursor chemical characterization $[\% \mathrm{w} / \mathrm{w}]$

\begin{tabular}{|c|c|c|c|c|c|c|c|c|c|c|c|c|}
\hline Precursor & Moisture & Ash & Fixed carbon & Volatile & Lignin & $\alpha$-celullose & $\beta$-cellullose & $\gamma$-celulosa & Holocellulose & Sugars & Fat & Reference \\
\hline Barley husk & 8.86 & 6.78 & 18.19 & 75.02 & 22.00 & 39.00 & - & - & - & $27.39 \pm 0.37$ & 4.00 & Kohli et al. 2013 \\
\hline Corn cob & 7.57 & 1.53 & - & - & 18.80 & 40.00 & - & - & - & 17.90 & 0.70 & Chen et al. 2014 \\
\hline Agave bagasse & - & 6.50 & - & - & 10.10 & 47.30 & - & - & - & $42.70 \pm 1.30$ & 2.80 & $\begin{array}{l}\text { Nieto-Delgado et al. } \\
2011\end{array}$ \\
\hline Cocoa shells & $9.15 \pm 0.78$ & $8.72 \pm 0.20$ & - & - & 16.87 & 18.87 & & & & - & - & Pereira et al. 2014 \\
\hline Siriguela seeds & $9.45 \pm 0.92$ & $2.05 \pm 0.25$ & - & - & 16.43 & 13.24 & - & - & - & - & - & Pereira et al. 2014 \\
\hline Barley husk & $7.38 \pm 0.05$ & $7.91 \pm 0.07$ & 4.86 & $79.84 \pm 0.10$ & $26.46 \pm 0.10$ & $66.69 \pm 0.04$ & $22.38 \pm 0.02$ & $10.92 \pm 0.03$ & $82.07 \pm 4.81$ & $27.44 \pm 0.05$ & $2.06 \pm 0.03$ & This study \\
\hline Corn cob & $6.91 \pm 0.07$ & $2.54 \pm 0.02$ & 6.09 & $84.46 \pm 0.34$ & $15.24 \pm 0.03$ & $52.60 \pm 0.11$ & $44.52 \pm 0.13$ & $2.89 \pm 0.03$ & $82.38 \pm 3.27$ & $19.34 \pm 0.17$ & $0.82 \pm 0.01$ & This study \\
\hline Agave leaves & $6.50 \pm 0.13$ & $9.92 \pm 0.05$ & 10.65 & $79.30 \pm 0.17$ & $15.58 \pm 0.15$ & $79.45 \pm 0.11$ & $13.18 \pm 0.15$ & $7.37 \pm 0.03$ & $83.05 \pm 3.34$ & $42.29 \pm 0.16$ & $1.68 \pm 0.01$ & This study \\
\hline
\end{tabular}

\section{Elemental analyses}

Biomass chemically is a complex composition of carbon, oxygen, hydrogen, nitrogen, sulfur, ash and small quantities of other elements such as alkali metals, alkali earth metals and heavy metals. The chemical composition of biomass mainly depends on the type of biomass, growing condition and geographic location (Espino et al. 2014). Carbon, hydrogen, oxygen and nitrogen contents of precursors compared with other biomass are shown in Table 2. As shown, the content of carbon is the highest share in most of biomass which is followed by oxygen and then hydrogen. Regarding the carbon contents, barley husk, corn cob and agave 
leaves presented values close, ranging 42-45\%. The present finding also support Nieto-Delgado et al. (2011) study which concluded that a good precursor of activated carbons should have a share of carbon in the range of $40-90 \%$ (Nieto-Delgado et al. 2011). The oxygen content of these biomass was the same, around 50\%. This share is followed by hydrogen content, around $6 \%$. In this sense, literature mentions that the proportion of carbon, oxygen and hydrogen is used to predict the heating value of the biomass and are the main contributors of the energy content in biomass (Tripathi et al. 2016). Furthermore, it is seen from Table 2 that high carbon and oxygen contents is the characteristic of woody and agricultural residues. Thus, the presence of this elements in the lignocellulosic precursors leads to more char formation as well as to the high calorific value of the carbonaceous materials obtained (Tripathi et al. 2016). In contrast nitrogen and sulfur are found in small found as shown un Table 2. Specifically, nitrogen was found in the precursors with values less than $1 \%$. This result is favorable since high contents of nitrogen and sulfur in biomass result in the release of gas mixtures of $\mathrm{SO}_{\mathrm{x}}$ and $\mathrm{NO}_{\mathrm{x}}$ during pyrolysis of the biomass, which are toxic and are not environment friendly (Tripathi et al. 2016). As shown, nitrogen content is very low in the precursors of this research, which provides evidence that pyrolysis of such precursor does not result in release of noxious gases. Thus, these findings also provide evidence that raw materials examined in this study are good precursors for the production of activated carbons.

Table 2 Carbon, oxygen, hydrogen, nitrogen and sulfur content [\%] in biomass obtained from different sources

\begin{tabular}{|c|c|c|c|c|c|c|c|c|}
\hline Biomass group & Biomass & Basis & $\mathrm{C}$ & $\mathrm{O}$ & $\mathrm{H}$ & $\mathrm{N}$ & $\mathrm{S}$ & Reference \\
\hline \multirow[t]{4}{*}{ Woody biomass } & Olive tree wood & Dry & 48.2 & 44.2 & 5.3 & 0.7 & 0.03 & Vamvuka and Zografos 2004 \\
\hline & Citrus tree wood & Dry & 47.0 & 43.2 & 5.3 & 0.7 & 0.08 & Vamvuka and Zografos 2004 \\
\hline & Spruce wood & Dry & 51.9 & 40.9 & 6.1 & 0.3 & - & Parikh et al. 2005 \\
\hline & Pine chips & Wet & 47.0 & 45.7 & 6.5 & 0.5 & 0.22 & Lapuerta et al. 2007 \\
\hline \multirow[t]{6}{*}{ Agricultural biomass } & Sugarcane bagasse & Dry and ash free & 48.7 & 44.1 & 6.7 & 0.5 & 0.08 & Islam et al. 2010 \\
\hline & Sunflower husk & Dry & 52.9 & 35.9 & 6.6 & 1.4 & 0.15 & Skoulou and Zabaniotou 2007 \\
\hline & Rice straw & Dry & 49.4 & 42.1 & 6.9 & 1.4 & 0.26 & Wu et al. 2009 \\
\hline & Barley husk & Dry and ash free & 42.08 & 50.95 & 6.32 & 0.65 & - & This study \\
\hline & Corn cob & Dry and ash free & 43.93 & 49.37 & 6.12 & 0.58 & - & This study \\
\hline & Agave leaves & Dry and ash free & 44.63 & 49.52 & 5.83 & 0.02 & - & This study \\
\hline
\end{tabular}

\section{Particle size}

Particles size is a factor which should be taken care in the activated carbon production as it can control the rate at which the heat is transferred to the input biomass. Alslaibi et al. (2013) indicates that particle size is a very important parameter in other processes of activated carbon preparation such as impregnation and activation. Figures $1 \mathrm{a}, 1 \mathrm{~b}$ and $1 \mathrm{c}$ show of particle size distribution for barley husk, corn cob and agave leaves, respectively. Particle sizes in the range of 390.9-610.7 $\mu \mathrm{m}$ were observed in the precursors materials. Specifically, corn cob had the smaller particle size to present a predominant mode of $390.9 \mu \mathrm{m}$. Particle sizes of $517.2 \mu \mathrm{m}$ were observed in agave leaves. In contrast, the distribution curve of particle sizes for barley husk showed a bimodal behavior, observing values from $390.9 \mu \mathrm{m}$ (most abundant) to $610.7 \mu \mathrm{m}$ (less abundant). According to the 
literature, particle sizes of 0.250 to $2.000 \mathrm{~mm}$ are suitable for the production of activated carbons (CanalesFlores and Prieto-García 2016). As shown, the particle size range of this study is within the range reported in the literature for other lignocellulosic precursors for activated carbon production.

Muller (2010) studied the effect of particle size on activated carbon adsorption. In this study, particle sizes in the ranges $63-100 \mu \mathrm{m}, 100-250 \mu \mathrm{m}$, and 250-500 $\mu \mathrm{m}$ were examined. The results showed that the adsorption rate increased with decreasing particle size. Thus, the best adsorption results were obtained with particle sizes of $82 \mu \mathrm{m}$. Similar effects were observed by Sentorun-Shalaby et al. (2006) who examined the effect of particle size on the properties of activated carbons. Three particle sizes were examined: $0.85 \mathrm{~mm}$ to $1.7 \mathrm{~mm}, 1.7 \mathrm{~mm}$ to $3.35 \mathrm{~mm}$, and $3.35 \mathrm{~mm}$ to $4.00 \mathrm{~mm}$. Their results revealed that the finer particles resulted in the development of larger surface areas and increased the percentage of micropores in the resulting activated carbons, which is a good agreement with the results of the present study. In contrast, Tripathi et al. (2016) added that although most of the reports show trend of high activated carbon yield on increasing particle size, few researchers have reported a reduction in the activated carbon yield on increasing the particle size of the lignocellulosic biomass. Therefore, the results of this study suggest that the particle sizes of precursors are suitable for the production of carbonaceous materials and are consistent with those shown in other research.
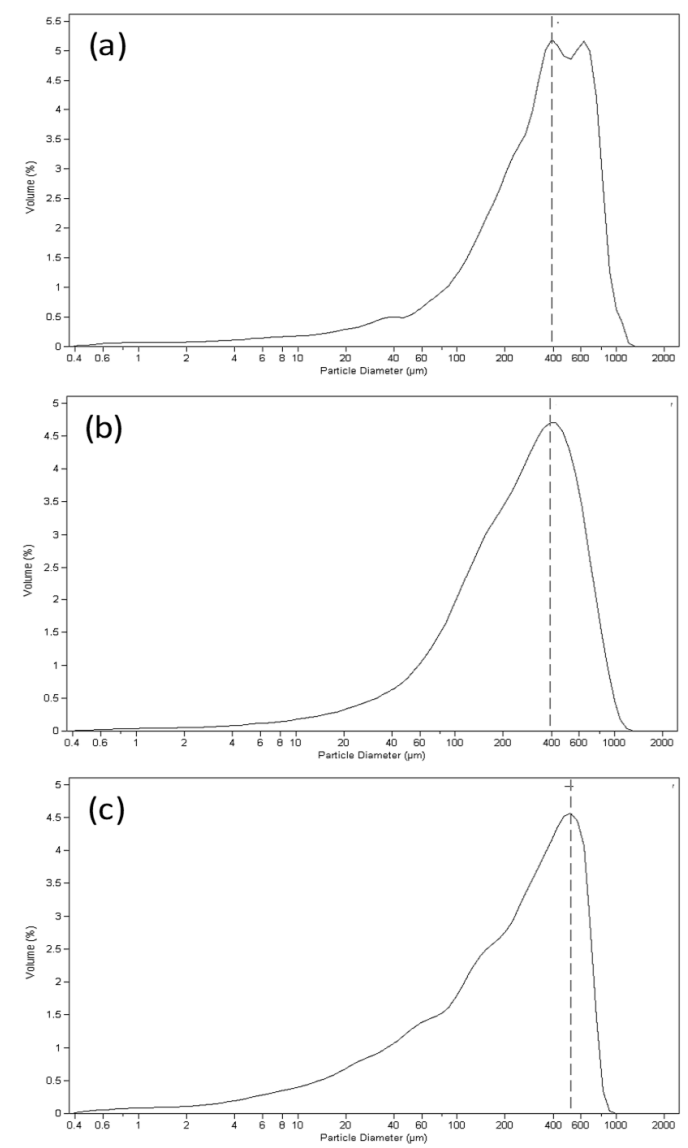

Fig 1 Particle size distribution of (a) barley husk, (b) corn cob and (c) agave leaves 


\section{Thermogravimetry}

As a representative result of the thermogravimetric analysis, Figures $2 \mathrm{a}-\mathrm{c}$ show profiles of fraction of the mass decrease of combustibles for barley husk (Fig. 2a), corb con (Fig. 2b) and agave leaves (Fig. 2c). These profiles are compared with the profile of cellulose (Fig. 2d) since the biomass studied in this work mainly consist of this compound as show in Table 1. The vertical axis represents fraction of mass decrease of combustibles. From the figures, the thermal decomposition of lignocellulosic compounds starts at about $180{ }^{\circ} \mathrm{C}$ for all the samples. According to the literature, the combustibles in the biomass react at the five stages during the thermal decomposition (Nieto-Delgado and Rangel-Méndez 2013). A first stage at temperature between $70{ }^{\circ} \mathrm{C}$ and 150 ${ }^{\circ} \mathrm{C}$ was observed which was attributed to moisture released and to the evaporation of some volatile compounds. The second stage (less pronounced than the previous one) was found from $180{ }^{\circ} \mathrm{C}$ to about $230{ }^{\circ} \mathrm{C}$, and was attributed to the degradation of hemicellulose. This stage was only detectable by thermo-gravimetric analyzer in the agave leaves. At the third stage, the mass rapidly decreases due to the cellulose volatilization. This main stage was observed in the temperature range of $250{ }^{\circ} \mathrm{C}$ to $350{ }^{\circ} \mathrm{C}$ for all the samples, and was representative of the thermal decomposition of cellulose. Specifically, peaks at $299{ }^{\circ} \mathrm{C}$ for barley husk, at $300{ }^{\circ} \mathrm{C}$ for corn cob, and at $326{ }^{\circ} \mathrm{C}$ for agave leaves were observed. Similar behaviors have been reported in other studies for the same precursors. For example, the profile DTGA of barley husk showed peaks for the thermal decomposition of cellulose at $245^{\circ} \mathrm{C}$ (Bledzki et al. 2010) and $357^{\circ} \mathrm{C}$ (Espino et al. 2014), corn cob at $340{ }^{\circ} \mathrm{C}$ (Bagheri and Abedi 2009), and agave bagasse around $300{ }^{\circ} \mathrm{C}$ (Nieto-Delgado et al. 2011), all obtained with heating rates of $10{ }^{\circ} \mathrm{C} \mathrm{min}-1$ under nitrogen. After that, the slow mass decrease occurs at the fourth stage between $380{ }^{\circ} \mathrm{C}$ and $550{ }^{\circ} \mathrm{C}$ due to lignin decomposition. Focusing on the pattern of the profile of mass decrease, trend of the mass decrease was similar at the third stage for all precursors. According to Gani and Naruse (2007), the cellulose decomposes at high decomposition rate within narrow temperature range, specifically $240-350{ }^{\circ} \mathrm{C}$ (NietoDelgado and Rangel-Méndez 2013). In contrast, lignin is the biomass fraction with the higher decomposition temperature $\left(280-500{ }^{\circ} \mathrm{C}\right)$, is harder to decompose than the cellulose and the hemicellulose since part of lignin consists of benzene rings, and is the fraction with higher carbon content (Gani and Naruse 2007; Nieto-Delgado and Rangel-Méndez 2013). Comparing these results for the biomass samples with those for the cellulose, the profiles for barley husk, corn cob and agave leaves approach to that for the cellulose (Fig. 2d). This is because the three precursors showed high cellulose content and low lignin content as shown in Table 1. Finally, the fifth stage was attributed to the ash derived from the degradation of complex polymers and inorganic salts present in the precursors, mainly in barley husk and agave leaves. These results are consistent with those reported by Gani and Naruse (2007) who suggest that the thermal behavior of biomass depends on its own component such as the cellulose and lignin content. Additionally, these findings provide valuable information regarding the thermal decomposition (pyrolysis) of the precursors studied in this work. 

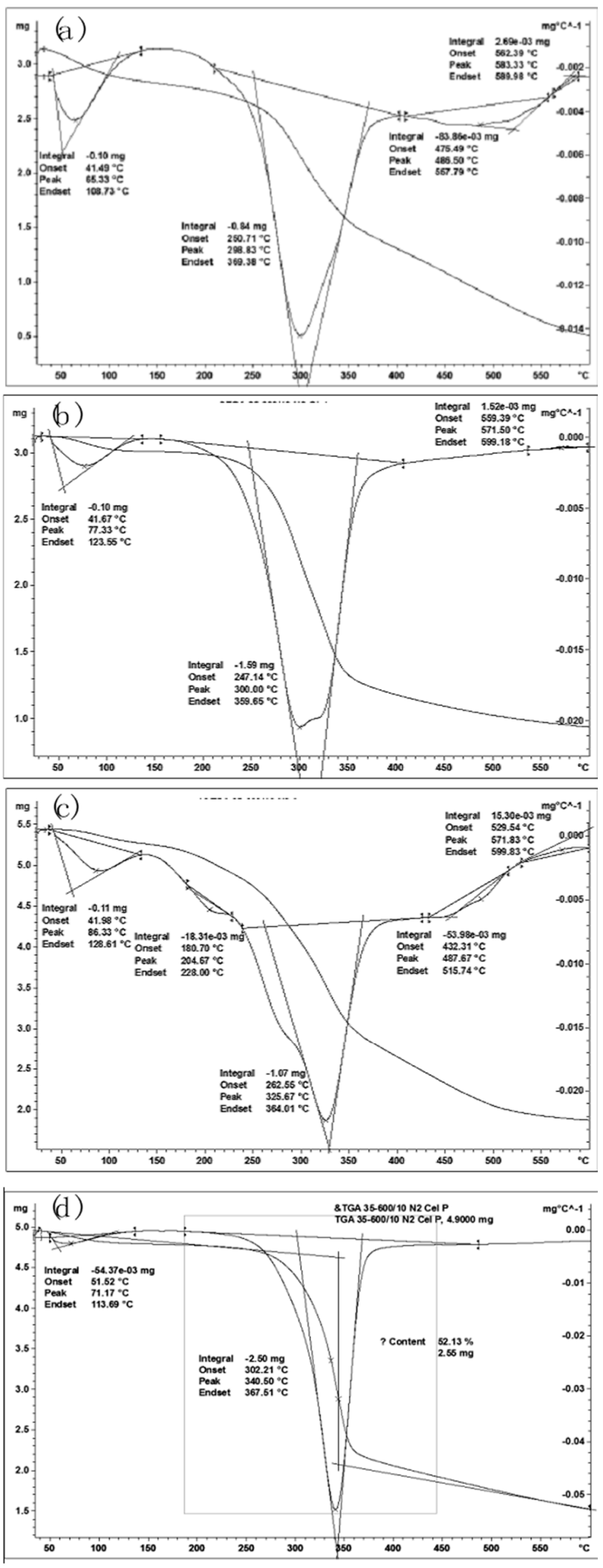

Fig. 2 Termogravimetric analysis of (a) barley husk, (b) corn cob, (c) agave leaves, and (d) cellulose 


\section{Fourier-transform infrared spectroscopy (FTIR)}

The FT-IR spectrum of the three precursors compared to cellulose is shown in Figure 3 and the assignment is given in Table 3. The peaks at $3425 \mathrm{~cm}^{-1}$ and $2919 \mathrm{~cm}^{-1}$ for barley husk, at $3425 \mathrm{~cm}^{-1}$ and $2918 \mathrm{~cm}^{-1}$ for corn cob, at $3424 \mathrm{~cm}^{-1}$ and $2919 \mathrm{~cm}^{-1}$ for agave leaves, and at $3435 \mathrm{~cm}^{-1}$ and $2923 \mathrm{~cm}^{-1}$ for cellulose were observed. The peak at about $3400 \mathrm{~cm}^{-1}$ is due to hydrogen bonded $\mathrm{O}-\mathrm{H}$ stretching. The hydrophilic tendency of the three precursors was reflected in the broad adsorption band, which is related to the $-\mathrm{OH}$ groups present in aliphatic or aromatic alcohol and present in their main components. The peak at around $2900 \mathrm{~cm}^{-1}$ is due to the C-H asymmetric and symmetric stretching from aliphatic saturated compounds. These two stretching peaks are corresponding to the aliphatic moieties in cellulose and hemicellulose. The peak at $2346 \mathrm{~cm}^{-1}$ was observed for the three precursors and at $2353 \mathrm{~cm}^{-1}$ for cellulose. On the other hand, the peaks at $2106 \mathrm{~cm}^{-1}$ for barley husk, at $2108 \mathrm{~cm}^{-1}$ for corn cob, at $2102 \mathrm{~cm}^{-1}$ for agave leaves, and at $2111 \mathrm{~cm}^{-1}$ for cellulose were observed. The sharp peaks at around $2340 \mathrm{~cm}^{-1}$ are attributed to the $\mathrm{P}-\mathrm{H}$ stretching and $\mathrm{P}-\mathrm{O}-\mathrm{H}$. The band at about $2112 \mathrm{~cm}^{-1}$ is attributed to the $\mathrm{Si}-\mathrm{H}$ stretching. According to Bledzki et al. (2010), the bands of this region are representative of inorganic hydride or oxide. In the double bond region, a shoulder peak at $1733 \mathrm{~cm}^{-1}$ for barley husk, at 1737 $\mathrm{cm}^{-1}$ for corn cob, at $1731 \mathrm{~cm}^{-1}$ for agave leaves and a peak at $1722 \mathrm{~cm}^{-1}$ for cellulose were assigned to the $\mathrm{C}=\mathrm{O}$ stretching of the acetyl and uronic ester groups of hemicellulose or to the ester linkage of carboxylic group of the $p$-cumaric acid of lignin. The sharp peaks at $1656 \mathrm{~cm}^{-1}$ for barley husk, at $1643 \mathrm{~cm}^{-1}$ for corn cob, and at $1635 \mathrm{~cm}^{-1}$ for agave and cellulose, are corresponding to amide I. The bands in the range $1375-1350 \mathrm{~cm}^{-1}$ were assigned from the $\mathrm{C}-\mathrm{H}$ symmetric and asymmetric deformations in methyl and phenolic alcohol. In the band region of $1250-1200 \mathrm{~cm}^{-1}$ represents $\mathrm{Si}-\mathrm{CH}_{2}$ stretching in alkane or $\mathrm{C}-\mathrm{C}$ plus $\mathrm{C}-\mathrm{O}$ plus $\mathrm{C}=\mathrm{O}$ stretching and deformation bands in cellulose and lignin (Chen et al. 2014). Barley husk, corn cob, agave leaves and cellulose showed an absorption peak at $1053 \mathrm{~cm}^{-1}, 1063 \mathrm{~cm}^{-1}, 1062 \mathrm{~cm}^{-1}$, and $1055 \mathrm{~cm}^{-1}$, respectively. The peak in the range 1086-1030 $\mathrm{cm}^{-1}$ was assigned to $\mathrm{C}-\mathrm{O}$ deformation in secondary alcohol and aliphatic ether. A sharp peak at around $900 \mathrm{~cm}^{-1}$ is representative of of the $\mathrm{C}-1$ groups frequency or ring frequency, and is characteristic of $\beta$-glycosidic linkages between the sugar units (Bledzki et al. 2010). In this sense, peaks at $908 \mathrm{~cm}^{-1}$ for barley husk, at $899 \mathrm{~cm}^{-1}$ for corn cob, at $917 \mathrm{~cm}^{-1}$ for agave leaves, and at $873 \mathrm{~cm}^{-1}$ for cellulose were observed.

As can be seen, the content of chemical components was similar but with different peak areas. In addition, FTIR spectrum were diffuse with a strong overlap of the peaks. The spectral differences were not well defined, which can be attributed to the high complexity of the various types of intermolecular and intramolecular interactions present in the lignocellulosic residues. 


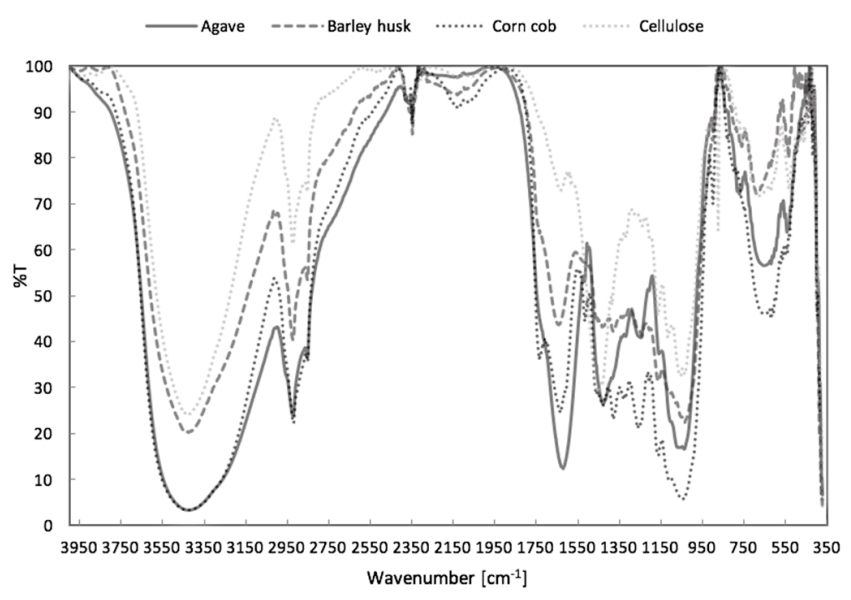

Fig. 3 FTIR spectra of the residue materials

Table 3 Attribution of the bands presented in the FTIR spectra

\begin{tabular}{|c|c|c|c|c|c|}
\hline \multicolumn{4}{|l|}{ Biomass } & \multirow{2}{*}{$\begin{array}{l}\text { Peak location } \\
\text { range }\left(\mathrm{cm}^{-1}\right)\end{array}$} & \multirow[t]{2}{*}{ Attribution } \\
\hline Barley husk & Corn cob & Agave leaves & Cellulose & & \\
\hline 3425 & 3425 & 3424 & 3435 & $3460-3400$ & $\mathrm{O}-\mathrm{H}$ stretching \\
\hline 2919 & 2918 & 2919 & 2923 & $3000-2850$ & $\begin{array}{l}\mathrm{C}-\mathrm{H} \text { asymmetric and symmetric stretching in methyl } \\
\text { and methylene group }\end{array}$ \\
\hline 2346 & 2346 & 2346 & 2353 & $2400-2300$ & $\mathrm{P}-\mathrm{H}$ stretching and $\mathrm{P}-\mathrm{O}-\mathrm{H}$ stretching \\
\hline 2106 & 2108 & 2102 & 2111 & $2200-2100$ & Si-H stretching \\
\hline 1733 & 1737 & 1731 & 1722 & $1738-1700$ & $\begin{array}{l}\mathrm{C}=\mathrm{O} \text { stretching in acetyl and uronic ester groups or } \\
\text { in carboxylic group of ferulic and cumaric acids }\end{array}$ \\
\hline 1656 & 1643 & 1635 & 1635 & $1650-1580$ & $\mathrm{~N}-\mathrm{H}$ bending in primary amine \\
\hline 1386 & 1383 & 1396 & 1344 & $1375-1350$ & $\begin{array}{l}\mathrm{C}-\mathrm{H} \text { rocking in alkanes or } \mathrm{C}-\mathrm{H} \text { stretching in methyl } \\
\text { and phenolic alcohol }\end{array}$ \\
\hline 1251 & 1266 & 1265 & 1241 & $1250-1200$ & $\begin{array}{l}\mathrm{Si}-\mathrm{CH}_{2} \text { stretching alkane or } \mathrm{C}-\mathrm{C} \text { plus } \mathrm{C}-\mathrm{O} \text { plus } \\
\mathrm{C}=\mathrm{O} \text { stretching }\end{array}$ \\
\hline 1053 & 1063 & 1062 & 1055 & $1086-1030$ & $\begin{array}{l}\mathrm{C}-\mathrm{O} \text { deformation in secondary alcohol and aliphatic } \\
\text { ether or aromatic }\end{array}$ \\
\hline 908 & 899 & 917 & 873 & $900-875$ & $\begin{array}{l}\mathrm{C}-\mathrm{H} \text { in plan deformation plus } \mathrm{C}-\mathrm{O} \text { deformation in } \\
\text { primary alcohol }\end{array}$ \\
\hline
\end{tabular}

\section{Scanning electron microscopy (SEM)}

Figures 4a-c show the surface morphology of the raw material of barley husk, corn cob and agave leaves, respectively. It can be observed that three lignocellulosic residues have fibrous and porous structure, which are suitable characteristics to obtain carbonaceous materials such as activated carbons (Canales-Flores and PrietoGarcía 2016), since biomass can easily decompose and burn. According to the literature, a good precursor of activated carbon must have a porous and fibrous structure, since under this condition, the oxygen can easily diffuse inside the particle during combustion, and volatile material can be gradually released. In addition, the 
combustion reactivity of lignocellulosic residues deeply relates to the activated carbon morphology formed (Gani and Naruse 2007). From this observation results, the three residues materials can be potential precursors of activated carbons.
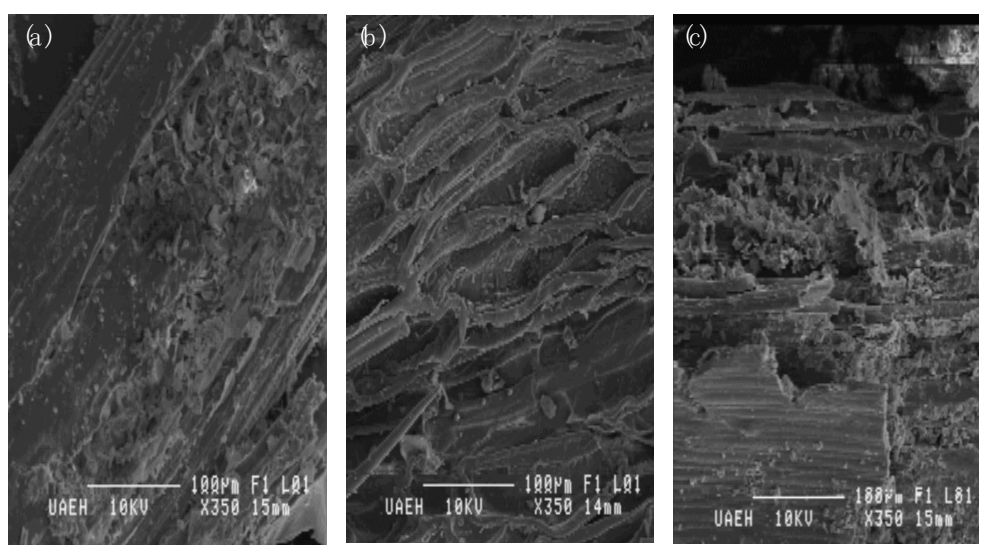

Fig. 4 Morphology of (a) barley husk, (b) corn cob, and (c) agave leaves

\section{Conclusion}

Barley husk, corn cob and Agave salmiana leaves were characterized to determine their chemical composition and morphology to evaluate their potentiality as precursors of activated carbons. Based on the main composition results obtained, the biomass samples have suitable chemical and physical characteristics to be considered as good precursors of activated carbons, such as carbon contents greater than $40 \%$, ash content less than $10 \%$, moisture content less than $30 \%$, high volatile contents with values from 75 to $80 \%$ and a porous and fibrous morphology. The results indicate that the main compositions in the biomass were cellulose and lignin. The cellulose content was more than lignin (15-26\%) for the residues selected. Specifically, $\alpha$-cellulose contents with values from $52 \%$ to $79 \%, \beta$-cellulose contents of $13-44 \%, \gamma$-cellulose contents less than $11 \%$, and holocellulose contents of $82-83 \%$ were determined. The thermal decomposition for the biomass samples proceeded with five stages attributed to the evaporation of some volatile compounds $\left(70-150{ }^{\circ} \mathrm{C}\right)$, to the degradation of hemicellulose $\left(180-230^{\circ} \mathrm{C}\right)$, to the cellulose volatilization $\left(250-350{ }^{\circ} \mathrm{C}\right)$, to the lignin decomposition $\left(380-550^{\circ} \mathrm{C}\right)$, and to the degradation of complex polymers and inorganic salts, respectively. The stage corresponding to the cellulose decomposition showed rapid mass decreased in the three residues. Therefore, it means that temperature of cellulose decomposition is the most suitable to promote the formation of char and to obtain high yields. This results show that the cellulose and lignin content in the biomass is another important parameter to evaluate the pyrolysis characteristics of a good precursor of activated carbon. From these findings, barley husk, corn cob and agave leaves can be considered as potential precursors of activated carbons. This research proposes viable and environmentally responsible solutions for the final disposal of this biomasses and for the production of value-added products such as activated carbon. 


\section{Acknowledgement section}

Corresponding author: Tel.: +52-771-7172000 ext 2287. E-mail: prietog@uaeh.edu.mx

\section{Acknowledgements}

This work was supported by the National Council of Science and Technology (CONACyT) [doctorate scholarship number 289880].

\section{References}

ASTM Standard D3172 (1997) Standard practice for proximate analysis of coal and coke. ASTM International, West Conshohocken, PA.

Bagheri N, Abedi J (2009) Preparation of high surface area activated carbon from corn by chemical activation using potassium hydroxide. Chem Eng Res Des 87:1059-1064. doi: 10.1016/j.cherd.2009.02.001

Bledzki AK, Mamum AA, Volk J (2010) Barley husk and coconut shell reinforced polypropylene composites: The effect of fibre physical, chemical and surface properties. Compos Sci Technol 70:840. doi: 10.1016/j.compscitech.2010.01.022

Canales-Flores RA, Prieto-García F (2016) Activation methods of carbonaceous materials obtained from agricultural waste. Chem Biodiversity 13:261-268. doi: 10.1002/cbdv.201500039

Chen G, Liu C, Ma W, Zhang X, Li Y, Yan B, Zhou W (2014) Co-pyrolysis of corn cob and waste cooking oil in a fixed bed. Bioresource Technol 166:500-507. doi: 10.1016/j.biortech.2014.05.090

Demirbas A (2004) Effect of initial moisture content on the yields of oily products from pyrolysis of biomass. J Anal Appl Pyrol 71:803-815. doi: 10.1016/j.jaap.2003.10.008

Espino E, Cakir M, Domenek S, Román-Gutiérrez AD, Belgacem N, Bras J (2014) Isolation and characterization of cellulose nanocrystals from industrial by-products of Agave tequilana and barley. Ind Crop Prod 62:552-559. doi: 10.1016/j.indcrop.2014.09.017

Gani A, Naruse I (2007) Effect of cellulose and lignin content on pyrolysis and combustion characteristics for several types of biomass. Renew Energ 32:649-661. doi: 10.1016/j.renene.2006.02.017

Islam MR, Parveen M, Haniu H (2010) Properties of sugarcane waste-derived bio-oils obtained by fixed-bed fire-tube heating pyrolysis. Bioresour Technol 101:4162-4168. doi: 10.1016/j.biortech.2009.12.137 Ioannidou O, Zabaniotou A (2007) Agricultural residues as precursors for activated carbon production-A review. Renew Sustain Energ Rev 11:1966-2005. doi: 10.1016/j.rser.2006.03.013

Khezami L, Chetouani A, Taouk B, Capart R (2005) Production and characterisation of activated carbon from wood components in powder: Cellulose, lignin, xylan. Powder Technol 157:48-56. doi: 10.1016/j.powtec.2005.05.009

Kohli D, Garg S, Jana AK (2013) Thermal and morphological properties of chemically treated barley husk fiber. Int J Res Mech Eng Technol 3:153-156.

Lapuerta M, Hernandez J, Rodriguez J (2007) Comparison between the kinetics of devolatilisation of forestry and agricultural wastes from the middle-south regions of Spain. Biomass Bioenerg 31:13-19. doi: 10.1016/j.biombioe.2006.05.003 
Muller BR (2010) Effect of particle size and surface area on the adsorption of albumin-bonded bilirubin on activated carbon. Carbon 48:3607-3615. doi: 10.1016/j.carbon.2010.06.011

Nieto-Delgado C, Rangel-Méndez JR (2013) Preparation of Carbon Materials from Lignocellulosic Biomass. In: Rufford TE (ed) Green Carbon Materials. Advanced and Aplications, Taylor \& Francis Group, US, pp 51. Nieto-Delgado C, Terrones M, Rangel-Mendez JR (2011) Development of highly microporous activated carbon from the alcoholic beverage industry organic by-products. Biomass Bioenerg 35:103-112. doi: 10.1016/j.biombioe.2010.08.025

Parikh J, Channiwala S, Ghosal G (2005) A correlation for calculating HHV from proximate analysis of solid fuels. Fuel 84:487-494. doi: 10.1016/j.fuel.2004.10.010

Pereira RG, Martins C, Mendes N, Farias L, Ferreira RC, Oliveira A, Oliveira M, da Costa R (2014) Preparation of activated carbons from cocoa shells and siriguela seeds using $\mathrm{H}_{3} \mathrm{PO}_{4}$ and $\mathrm{ZnCl}_{2}$ as activating agents for BSA and $\alpha$-lactalbumin adsorption. Fuel Process Technol 126:476-486. doi: 10.1016/j.fuproc.2014.06.001

Savova D, Apak E, Ekinci E, Yardim F, Petrov N, Budinova T, Razvigorova M, Minkova V (2001) Biomass conversion to carbon adsorbents and gas. Biomass Bioenerg 21:133-142. doi: 10.1016/S0961-9534(01)000277

Sentorun - Shalaby C, Artok L, Sarici C (2006) Preparation and characterization of activated carbons by onestep steam pyrolysis/activation from apricot stones. Micropor Mesopor Mat 88:126-134. doi: 10.1016/j.micromeso.2005.09.003

Skoulou V, Zabaniotou A (2007) Investigation of agricultural and animal wastes in Greece and their allocation to potential application for energy production. Renew Sustain Energ Rev 11:1698-1719. doi: 10.1016/j.rser.2005.12.011

Stefanidis SD, Kalogiannis KG, Iliopoulou EF, Michailof CM, Pilavachi PA, Lappas AA (2014) A study of lignocellulosic biomass pyrolysis via the pyrolysis of cellulose, hemicellulose and lignin. J Anal Appl Pyrol 105:143-150. doi: 10.1016/j.jaap.2013.10.013

TAPPI T203 (1999) Alpha-, beta- and gamma-cellulose in pulp. TAPPI Press, Norcross, Georgia.

TAPPI T204 (1997) Solvent extractives of wood and pulp. TAPPI Press, Norcross, Georgia.

TAPPI T222 (1998) Acid-insoluble lignin in wood and pulp. TAPPI Press, Norcross, Georgia.

Tripathi M, Shahu JN, Ganesan P (2016) Effect of process parameters on production of biochar from biomass waste through pyrolysis: A review. Renew Sust Ener Rev 55:467-481. doi: 10.1016/j.rser.2015.10.122

Vamvuka D, Zografos D (2004) Predicting the behaviour of ash from agricultural wastes during combustion. Fuel 83:2051-2057. doi: 10.1016/j.fuel.2004.04.012

Wise LE, Marphy M, d'Adieco A (1946) A chlorite holocellulose, its fractionation and bearing on summative wood analysis and studies on the hemicelluloses. Pap Trade J 122:35-43.

Wu Y, Wu S, Li Y, Gao J (2009) Physico-chemical characteristics and mineral transformation behavior of ashes from crop straw. Energ Fuels 23:5144-5150. doi: 10.1021/ef900496b

Xiong S, Zhuo J, Zhang B, Yao Q (2013) Effect of moisture content on the characterization of products from the pyrolysis of sewage sludge. J Anal Appl Pyrol 104:632-639. doi: 10.1016/j.jaap.2013.05.003 